\title{
Analysis on Regional Differences of China's Medical and Health Development Level
}

\author{
Yulu Zhang ${ }^{1}$, Shengxi Ding ${ }^{2 *}$ \\ ${ }^{1,2}$ School of Finance and Economics, Qinghai University, Xining, Qinghai, China
}

\begin{abstract}
Since the reform and opening up, China's economy has developed rapidly. At the same time, China's medical and health services have also made great progress. However, the outbreak of the new crown epidemic has exposed many problems such as the uncoordinated development of China's medical and health regions. SPSS22.0 and Geoda software analyze the differences in the medical and health development levels of China's 31 provincial administrative regions, and then propose corresponding policy recommendations.
\end{abstract}

\section{Introduction}

Since the reform and opening up, China's medical and health industry has achieved rapid development, and the main health indicators of residents are generally better than the average level of middle- and high-income countries ${ }^{[1]}$. With the rapid economic and social development, the growth of medical and health demand and the change of disease spectrum, people are more concerned about the development of medical and health, at the same time, the status of medical and health development in the regional economic and social development is becoming more and more important. However, due to differences in regional economic development levels, cultural history, policy systems and other factors, there are great differences in the level of medical and health development between regions. The outbreak of new coronary pneumonia has exposed problems such as uneven and insufficient development among regions.

For the analysis of China's medical and health development, most domestic scholars use qualitative, quantitative or a combination of qualitative and quantitative analysis methods. When analyzing differences in medical and health between regions, they use Theil index, Moran index, and coefficient of variation to evaluate them. Shang Hongyun (2006) found through Q-type clustering analysis that in terms of medical and health resource allocation structure, there are problems such as large regional differences, east-west differentiation of medical service levels, and an imbalance in the allocation of urban and rural health resources ${ }^{[2]}$. Huang Xiaoping (2008) used the Theil index to analyze the public health expenditure in China in order to study the fairness of medical resource allocation and pointed out that the imbalance of regional economic development has exacerbated the difference in public health expenditure ${ }^{[3]}$. In addition to the overall research on the regional differences in medical and health resources, some scholars also analyze individual factors and propose specific optimization measures. Cheng Qianchang (2019) started from the perspective of the spatial distribution of medical and health technicians and found that Chinese health technicians present the characteristics of a dual structure of urban and rural areas, and the gap between regions is very prominent ${ }^{[4]}$. However, the current research on regional differences in the level of medical and health development focuses more on the results of differentiation rather than the causes of such differences, and also ignores the relationship between the level of medical and health development and its development results. Dong Enhong et al. (2016) reviewed the research on the differentiation of medical and health resource allocation by domestic and foreign scholars, and pointed out that the transformation of health outcomes of medical and health resources is the direction of future research ${ }^{[5]}$.

On the basis of existing related research, this article constructs an evaluation index system, uses factor molecular and spatial difference analysis to comprehensively evaluate the medical and health development level of China's 31 provincial administrative regions, and provides relevant departments for the balanced development of regional medical and health resources. Decision-making reference.

\section{Overview of China's medical and health development}

In recent years, with the development of China's national economy and the improvement of people's living standards, people's health awareness has increased, and the demand for medical services has continued to be released. In this context, while China's medical and

11342315143@qq.com ㄹCorresponding author:1063013260@qq.com 
health resources continue to grow and China's medical service system is more complete and complete, there are also large differences in the level of medical and health development in various regions.

In 2018, the number of medical and health institutions in China was 997,433, of which the number of medical and health institutions in the eastern region was 373,998 , accounting for $37.50 \%$; the number of medical and health institutions in the central region was 310665 , accounting for $31.14 \%$; The number of medical and health institutions in the western region is 312,770 , accounting for $31.36 \%$. The proportion of medical and health institutions in the eastern and central regions is lower than the proportion of the population, the proportion of medical and health institutions in the western region is much higher than the proportion of the population, and the resources of medical and health institutions in the western region are relatively abundant. Among the 31 provincial administrative regions, the area with the highest per capita health care expenditure is Beijing (Eastern Region), which reaches 3274.5 yuan, and the area with the lowest per capita health care expenditure is Tibet (Western Region), which is 460.1 yuan, which is insufficient $15 \%$ of Beijing. The per capita health care expenditures in different regions are very different. The per capita health care expenditures in the eastern, central and western regions are 1989.91 yuan, 1678.76 yuan, and $1,452.49$ yuan respectively. The expenditure is 1.19 times and 1.40 times that of the central and western regions respectively.

The 31 provincial administrative regions have a large gap in their total health expenditure in their GDP. Among them, Tibet's total health expenditure accounts for $10.63 \%$ of GDP, ranking first among 31 regions; Jiangsu's total health expenditure accounts for $4.3 \%$ of GDP. Ranked 31 st. It can be seen from Figure 3 that the total health expenditure in the western region as a percentage of GDP is generally higher than that in the eastern and central regions, which is inseparable from the emphasis on medical and health and the degree of local economic development. As one of the three core indicators of the United Nations Human Development Index, average life expectancy reflects the overall health level of a region. One of the four basic paths proposed by the "Healthy China" initiative is to extend healthy lifespan. Among the 31 provincial administrative regions, the area with the highest average life expectancy is Shanghai, which is as high as 80.26 years old. The area with the lowest average life expectancy is 1.18 times that of 68.17 years old in Tibet. The average life expectancy in the eastern region is between 75 and 81 years old, which is generally higher than that in the central and western regions. This is not only affected by the climate and other natural conditions in the region, but also closely related to the level of medical and health development in the region. Therefore, it is very important to analyze the differences in medical and health development between regions and put forward corresponding countermeasures and suggestions.

\section{Data indicators and descriptions}

The data indicators and generated data indicators in the article are from the "China Health Statistics Yearbook (2019)" and "China Statistics Yearbook (2019)".

Based on the principles of scientificity, comparability, and availability of data, the following evaluation system is constructed.

Table 1 Regional comprehensive evaluation index system of medical and health resources

\begin{tabular}{|c|c|c|}
\hline $\begin{array}{l}\text { First level } \\
\text { indicator }\end{array}$ & Secondary indicators & variables \\
\hline \multirow[t]{4}{*}{$\begin{array}{l}\text { Medical } \\
\text { and health } \\
\text { resources }\end{array}$} & $\begin{array}{c}\text { Number of medical and health } \\
\text { institutions per } 10,000 \text { population } \\
\text { (units) }\end{array}$ & $\mathrm{X}_{1}$ \\
\hline & $\begin{array}{l}\text { Number of beds in medical and health } \\
\text { institutions per thousand population } \\
\text { (pieces) }\end{array}$ & $\mathrm{X}_{2}$ \\
\hline & $\begin{array}{l}\text { Health technical personnel per } \\
\text { thousand population (person) }\end{array}$ & $\mathrm{X}_{3}$ \\
\hline & Number of tertiary hospitals (units) & $\mathrm{X}_{4}$ \\
\hline \multirow[t]{4}{*}{$\begin{array}{l}\text { Healthcare } \\
\text { capabilities }\end{array}$} & $\begin{array}{l}\text { Per capita health care expenditure } \\
\text { (yuan) }\end{array}$ & $\mathrm{X}_{5}$ \\
\hline & $\begin{array}{l}\text { Total health expenditure per capita } \\
\text { (yuan) }\end{array}$ & $\mathrm{X}_{6}$ \\
\hline & $\begin{array}{c}\text { Proportion of total health expenditure } \\
\text { in GDP }(\%)\end{array}$ & $\mathrm{X}_{7}$ \\
\hline & Average life expectancy (years) & $\mathrm{X}_{8}$ \\
\hline \multirow{2}{*}{$\begin{array}{l}\text { Medical } \\
\text { and health } \\
\text { services }\end{array}$} & $\begin{array}{l}\text { Percentage of people served by } \\
\text { medical and health institutions }(\%)\end{array}$ & $\mathrm{X}_{9}$ \\
\hline & $\begin{array}{l}\text { Physicians are responsible for the } \\
\text { number of visits per day (times) }\end{array}$ & $\mathrm{X}_{10}$ \\
\hline
\end{tabular}

\section{Factor Analysis of regional differences in medical and health resources}

In this section, SPSS22.0 software is used to evaluate the medical and health development level of China's 31 provincial administrative regions using the factor molecular method, and the comprehensive scores are used to judge the level of the medical and health development level of each provincial administrative region, thereby promoting resources for relevant departments Equalization provides a basis for decision-making.

After passing the correlation test, three common factors are extracted, the factor expression is established according to the component score coefficient matrix, and the component score is calculated.

$\mathrm{F} 1=-0.015 \mathrm{X} 1-0.145 \mathrm{X} 2+0.220 \mathrm{X} 3-0.167 \mathrm{X} 4+0.083 \times 5+$ $0.296 \times 6+0.093 \times 7+0.049 \times 8+0.282 \times 9+0.287 \times 10$

$\mathrm{F} 2=-0.258 \mathrm{X} 1+0.090 \times 2-0.200 \times 3+0.357 \mathrm{X} 4+0.117 \times 5-$

$0.139 \times 6-0.363 \times 7+0.257 \times 8-0.025 \times 9-0.025 \times 10$

$\mathrm{F} 3=-0.010 \mathrm{X} 1+0.629 \mathrm{X} 2+0.178 \mathrm{X} 3+0.171 \mathrm{X} 4+0.299 \times 5$

$+0.039 \times 6+0.107 \times 7+0.057 \times 8-0.159 \times 9-0.286 \times 10$

$\mathrm{F}=(36.466 * \mathrm{~F} 1+25.972 \mathrm{~F} 2+16.685 * \mathrm{~F} 3) / 79.124$

Finally, the 31 provincial administrative regions in China are ranked in descending order according to the scores. The higher the score, the stronger the comprehensive medical and health strength of the administrative region, and vice versa.

Table 2 Comprehensive medical and health rankings of China's provincial administrative regions

\begin{tabular}{|l|l|l|l|l|l|l|l|}
\hline Regions & $F_{1}$ & Rank & $F_{2}$ & Rank & $F_{3}$ & Rank & F \\
\hline
\end{tabular}




\begin{tabular}{|c|c|c|c|c|c|c|c|c|}
\hline Beijing & 3.214 & 1 & -0.355 & 22 & 1.856 & 2 & 1.756 & 1 \\
\hline Tianjin & 1.259 & 4 & 0.862 & 4 & -1.033 & 24 & 0.645 & 4 \\
\hline Hebei & -0.528 & 24 & -0.046 & 20 & -0.531 & 22 & -0.371 & 23 \\
\hline Shanxi & -0.777 & 27 & -0.346 & 21 & 0.032 & 17 & -0.465 & 26 \\
\hline Neimenggu & -0.480 & 21 & -0.036 & 19 & 0.635 & 9 & -0.099 & 17 \\
\hline Liaoning & -0.828 & 29 & 0.836 & 6 & 1.997 & 1 & 0.314 & 7 \\
\hline Jilin & -0.518 & 23 & 0.135 & 17 & 0.811 & 6 & -0.023 & 14 \\
\hline Heilongjiang & -0.997 & 31 & 0.584 & 8 & 1.521 & 3 & 0.053 & 11 \\
\hline Shanghai & 3.049 & 2 & 0.378 & 13 & -0.256 & 21 & 1.475 & 2 \\
\hline Jiangsu & 0.226 & 8 & 1.491 & 2 & 0.067 & 16 & 0.608 & 5 \\
\hline Zhejiang & 1.367 & 3 & 0.843 & 5 & -0.084 & 20 & 0.889 & 3 \\
\hline Anhui & -0.651 & 25 & 0.512 & 10 & -1.135 & 26 & -0.371 & 24 \\
\hline Fujian & 0.000 & 10 & 0.557 & 9 & -1.625 & 31 & -0.160 & 18 \\
\hline Jiangxi & -0.821 & 28 & 0.381 & 12 & -1.537 & 30 & -0.577 & 29 \\
\hline Shandong & -0.463 & 20 & 1.145 & 3 & 0.203 & 14 & 0.205 & 8 \\
\hline Henan & -0.411 & 19 & 0.329 & 15 & -0.072 & 19 & -0.096 & 16 \\
\hline Hubei & -0.267 & 16 & 0.726 & 7 & 0.135 & 15 & 0.144 & 9 \\
\hline Hunan & -0.990 & 30 & 0.377 & 14 & 0.494 & 10 & -0.228 & 20 \\
\hline Guangdong & 0.255 & 6 & 1.505 & 1 & -1.397 & 28 & 0.317 & 6 \\
\hline Guangxi & -0.078 & 12 & 0.027 & 18 & -1.456 & 29 & -0.334 & 22 \\
\hline Hainan & 0.206 & 9 & -0.537 & 24 & -1.084 & 25 & -0.310 & 21 \\
\hline Chongqing & -0.214 & 14 & 0.227 & 16 & 0.281 & 11 & 0.035 & 12 \\
\hline Sichuan & -0.486 & 22 & 0.457 & 11 & 0.811 & 7 & 0.097 & 10 \\
\hline Guizhou & -0.694 & 26 & -0.602 & 25 & 0.214 & 13 & -0.472 & 27 \\
\hline Yunnan & -0.262 & 15 & -0.724 & 26 & -0.567 & 23 & -0.478 & 28 \\
\hline Tibet & 0.230 & 7 & -3.410 & 31 & -1.378 & 27 & -1.304 & 31 \\
\hline Shanxi(陕) & -0.047 & 11 & -0.385 & 23 & 0.804 & 8 & 0.022 & 13 \\
\hline Gansu & -0.322 & 18 & -1.270 & 29 & -0.062 & 18 & -0.578 & 30 \\
\hline Qinghai & -0.086 & 13 & -1.785 & 30 & 0.981 & 5 & -0.419 & 25 \\
\hline Ningxia & 0.386 & 5 & -0.900 & 27 & 0.274 & 12 & -0.060 & 15 \\
\hline Xinjiang & -0.273 & 17 & -0.976 & 28 & 1.104 & 4 & -0.214 & 19 \\
\hline
\end{tabular}

It can be seen from Table 2 that Beijing has a comprehensive score of 1.756 , which is the highest score among the 31 provincial administrative regions. Shanghai and Zhejiang followed closely with scores of 1.475 and 0.889 . The top regions were mostly concentrated in the east; the five provincial administrative regions at the bottom were Guizhou, Yunnan, Jiangxi, Gansu, and Tibet, with scores of -0.472 . $,-0.475,-0.577,-0.578$ and -1.304 , the lower-ranking regions are mostly concentrated in the central and western regions, and there is a large regional gap in the level of medical and health development in China.

\section{Analysis of spatial differences in medical and health development levels}

The above analysis shows that China's medical and health development level may have spatial agglomeration. Therefore, this section uses Geoda software to analyze the spatial difference in medical and health development levels based on the F-values of the 31 provincial administrative regions in the previous section.

The first is the spatial correlation analysis. Moran's $\mathrm{I}=0.284$ indicates that the $\mathrm{F}$ variables of 31 provincial administrative regions have a positive spatial autocorrelation relationship in the spatial distribution, that is, there is spatial dependence, indicating that the provincial $\mathrm{F}$ variables are not random in the spatial distribution It is distributed, but it shows the phenomenon that some provincial administrative regions $F$ variables tend to agglomerate in space.

Local spatial autocorrelation is also a method of spatial data analysis. Based on the above spatial correlation analysis, it can be seen from the LISA cluster map that Shanghai and Jiangsu are in high-high clusters;
Qinghai, Xinjiang, and Tibet are in low-low clustering; Sichuan is in a high-low cluster, the clustering is consistent with the Moran scatter plot.

On the basis of spatial clustering, the medical and health development level of China's 31 provincial administrative regions is divided into five levels from high scores to low scores according to equal discontinuities, and the above five levels show obvious regional clustering. The first level includes Beijing and Shanghai, with a high level of medical and health development; the second level includes Tianjin, Jiangsu and Zhejiang, where the medical and health development is relatively good, second only to Beijing and Shanghai, the third level includes Guangdong, Liaoning, Shandong and other 15 provincial administrative regions belong to the medium-sized medical and health development regions. The fourth level includes 10 provincial administrative regions such as Hainan, Guangxi, and Hebei. The level of medical and health development at this level is relatively low and medical and health resources are relatively lacking. The fifth level only includes Tibet, where the level of medical and health development is low.

\section{Conclusions and recommendations}

\subsection{Conclusion}

Through Factor Analysis and spatial correlation analysis, the medical and health development level of China's 31 provincial administrative regions is evaluated. The evaluation results show that the medical and health development level of 31 provincial administrative regions has obvious geographical imbalance in space. It is divided into five levels according to equal discontinuities, and then the five levels are evaluated for 
the level of development, of which the level of medical and health development Five regions such as Beijing and Shanghai are high, and 15 regions such as Guangdong and Liaoning are in the middle-ranking medical and health development; 11 regions such as Hainan and Guangxi are relatively low in medical and health development. There is a situation where the two ends are small and the middle is big and present a clear agglomeration effect in space.

\subsection{Suggestions}

Pay attention to the improvement of weight and quality to narrow the gap between regions. On the one hand, regions should train more medical and health technical personnel and build more medical and health institutions to meet people's health needs [6]; on the other hand, they should also focus on the improvement and renewal of medical equipment in medical and health institutions. To improve the capabilities of medical and health technical personnel, while encouraging independent research and development and the introduction of advanced medical equipment, medical personnel should also be encouraged to continue their studies and improve their own technical level.

Actively carry out the equalization of public services and reduce the inter-provincial gap [7]. The equalization of public services should not be allocated according to the regional economic development capacity, but should be allocated according to the permanent population. This requires the state to support the construction of areas with backward medical and health development from the institutional level, and provide financial guarantees and technical support for them. While promoting the improvement of medical and health capacity in the region, it also narrowed the gap between provinces.

Build a government-use industry-university-research collaborative innovation system to promote the development of the big health industry. Actively building an innovative system for the coordinated development of government, industry, academia, and research, and developing a large-scale health industry are very important to ensure people's lives, health and safety, and improve regional medical and health standards. In Tibet, Gansu, Jiangxi and other areas with low levels of medical and health development, the above-mentioned provinces must establish an industry-university-research cooperative innovation system used by the government according to their own conditions. Cooperate with domestic and foreign countries to promote complementary advantages and resource sharing, and promote the improvement of medical and health standards in depth and breadth.

\section{References}

1. The State Council. Opinions of the State Council on Implementing the Healthy China Action [Z]. 2019-07-15.

2. Shang, H.Y. An Empirical Study on the Regional Differences of China's Medical and Health Industry
Development [J]. Journal of Dongbei University of Finance and Economics, 2006 (6): 71-75.

3. Huang, X.P, Fang, Q.Y. , egional differences in China's financial support for medical and health care-Based on the perspective of Theil index expenditure [J]. Financial Research, 2008 (4): 42-45.

4. Cheng, Q.C. Regional differences and structural optimization of Chinese health technicians[J]. Decision Consulting, 2019 (1): 92-96.

5. Dong, E.H, Li, G.H, etc. A review of research on regional differentiation of medical and health resource allocation $[\mathrm{J}]$. China Health Resources, 2016 (9): 390-393.

6. Ma, J.X. Public health expenditure, health capital and economic growth_-based on the empirical analysis of western my country [D]. Beijing: Central University of Finance and Economics, 2015.

7. Yang, C.Y. Challenges and decision-making in the allocation of public service resources in the process of urbanization [J]. Gansu Social Sciences, 2014 (4): 9-13. 